Supporting Information

\title{
Pure Siliceous Zeolite-supported Ru Single-atom Active Sites for Ammonia Synthesis
}

Jiang-Zhen Qiu, ${ }^{\dagger}$ Jibo Hu ${ }^{\dagger}$ Jinggang Lan,$\leftleftarrows$ Long-Fei Wang,${ }^{\dagger}$ Guangying Fu,${ }^{\dagger}$ Rujian Xiao, ${ }^{\dagger}$ Binghui $\mathrm{Ge},{ }^{\S}$ and Jiuxing Jiang ${ }^{\dagger *}$

$\uparrow$ MOE Key Laboratory of Bioinorganic and Synthetic Chemistry, School of Chemistry, Sun Yatsen University, Guangzhou, 510275, P. R. China.

:Department of Chemistry, University of Zurich, Winterthurerstrasse 190, CH-8057 Zurich,

Switzerland

§Institutes of Physical Science and Information Technology, Anhui University, Hefei 230601, P. R. China. 


\section{Supplementary Figures}

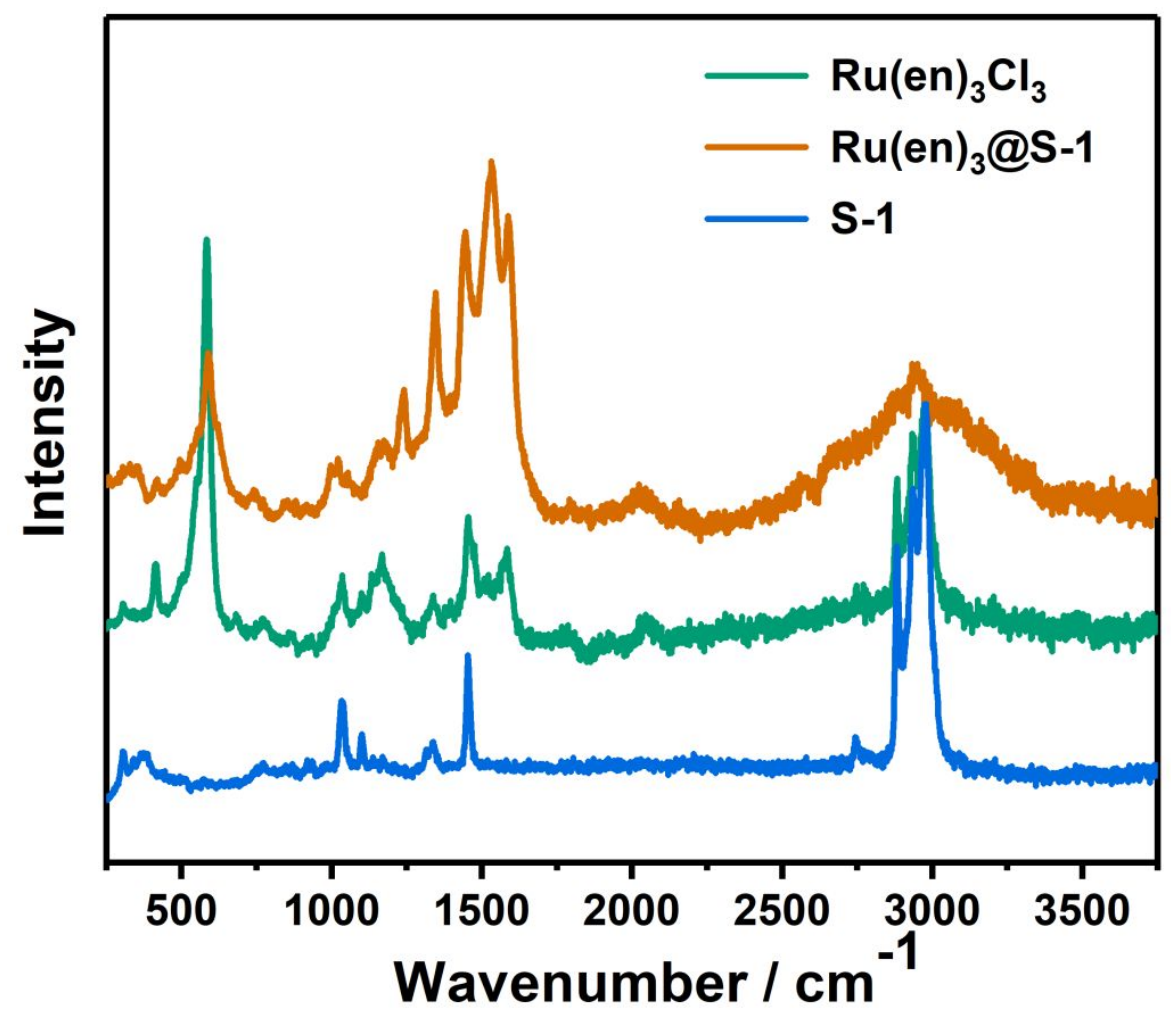

Figure S1. Raman spectra of $\mathrm{Ru}(\mathrm{en})_{3} @ \mathrm{~S}-1, \mathrm{Ru}(\mathrm{en})_{3} \mathrm{Cl}_{3}$ and $\mathrm{S}-1$, respectively. The Ru(en) $)_{3}$ S-1 and S-1 samples used for Raman spectra measurements are as-synthesized with the OSDA and amine. In comparison with the Raman spectra of S-1 sample, the Raman spectra of Ru(en) $)_{3} @ \mathrm{~S}-1$ show similar characteristic peaks at $585 \mathrm{~cm}^{-1}$, indicating the successful encapsulating of $\mathrm{Ru}(\mathrm{en})_{3}{ }^{+}$within S-1 zeolite structure as expected. 

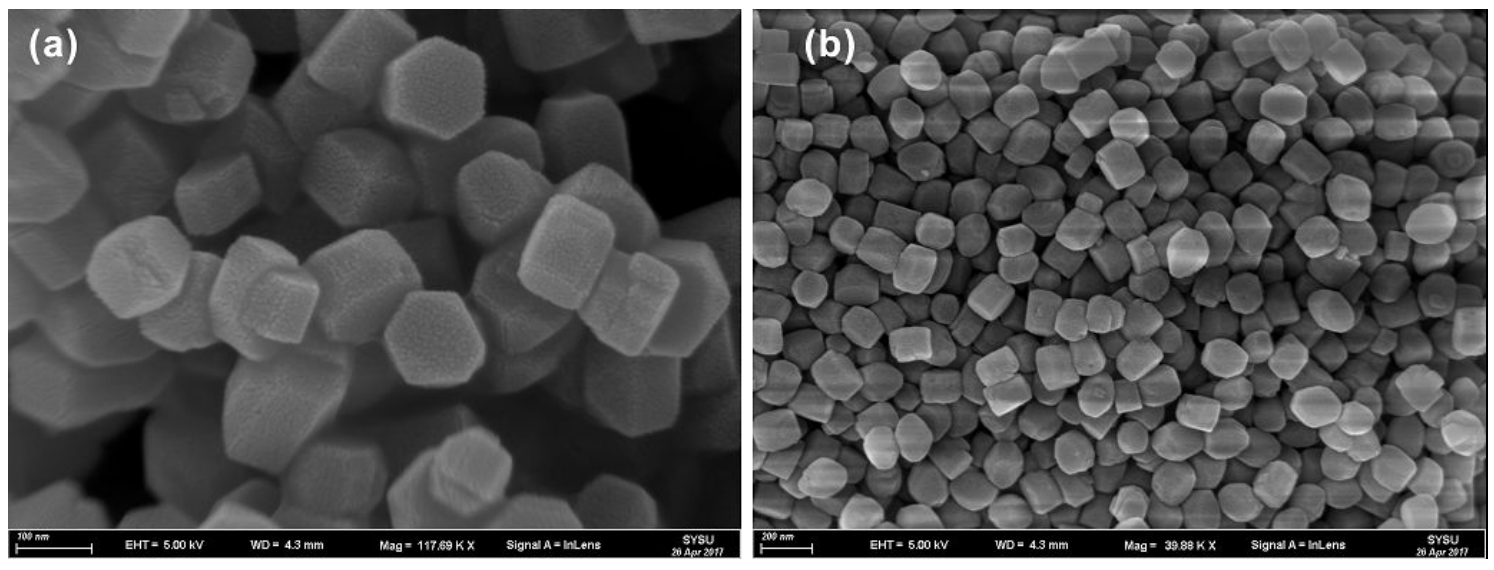

Figure S2. The SEM images of Ru SAs/S-1 $(a, b)$. Obviously, the Ru SAs/S-1 samples are hexagonal prism morphology with uniform nanometer size of around $200 \mathrm{~nm}$. 


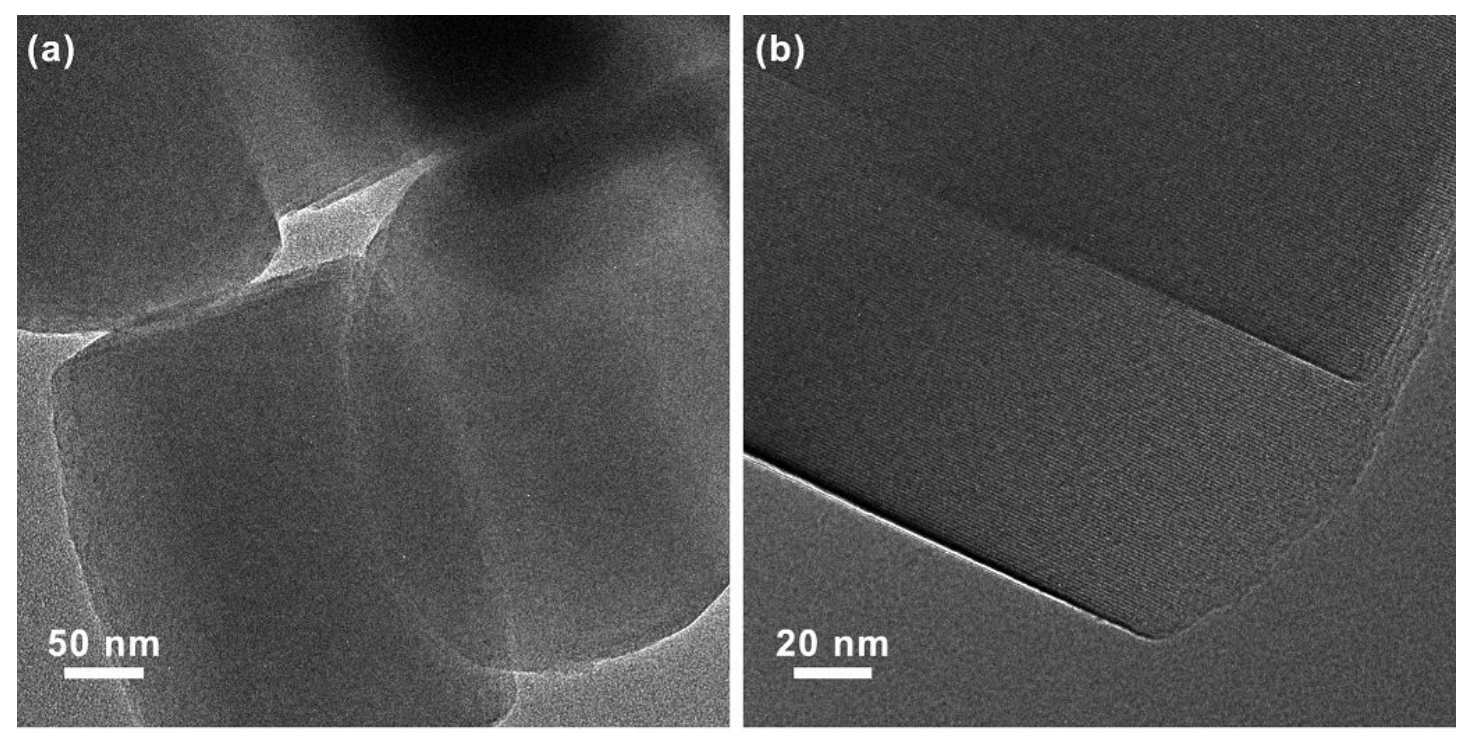

Figure S3. TEM $(a, b)$ images of Ru SAs/S-1. In the TEM images, subnanometer clusters and nanoparticles within the zeolite crystals or outside the external surface are not observed. 


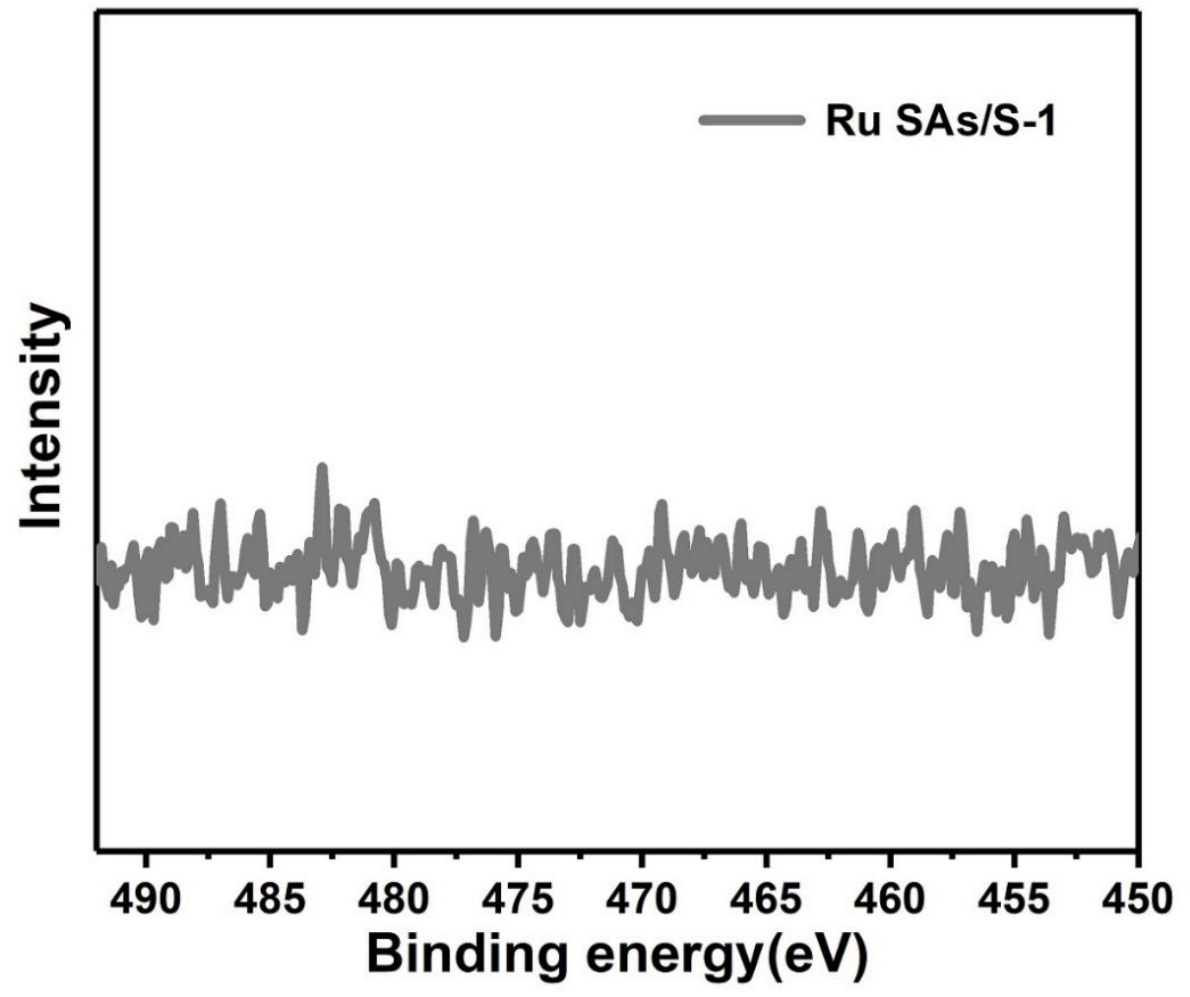

Figure S4. Ru 3p XPS spectrum of Ru SAs/S-1. No signals in Ru 3p regions is observed, revealing the absence of any nanoparticles outside the surface of Ru SAs/S-1, which is in accordance with the results from TEM and STEM images. 


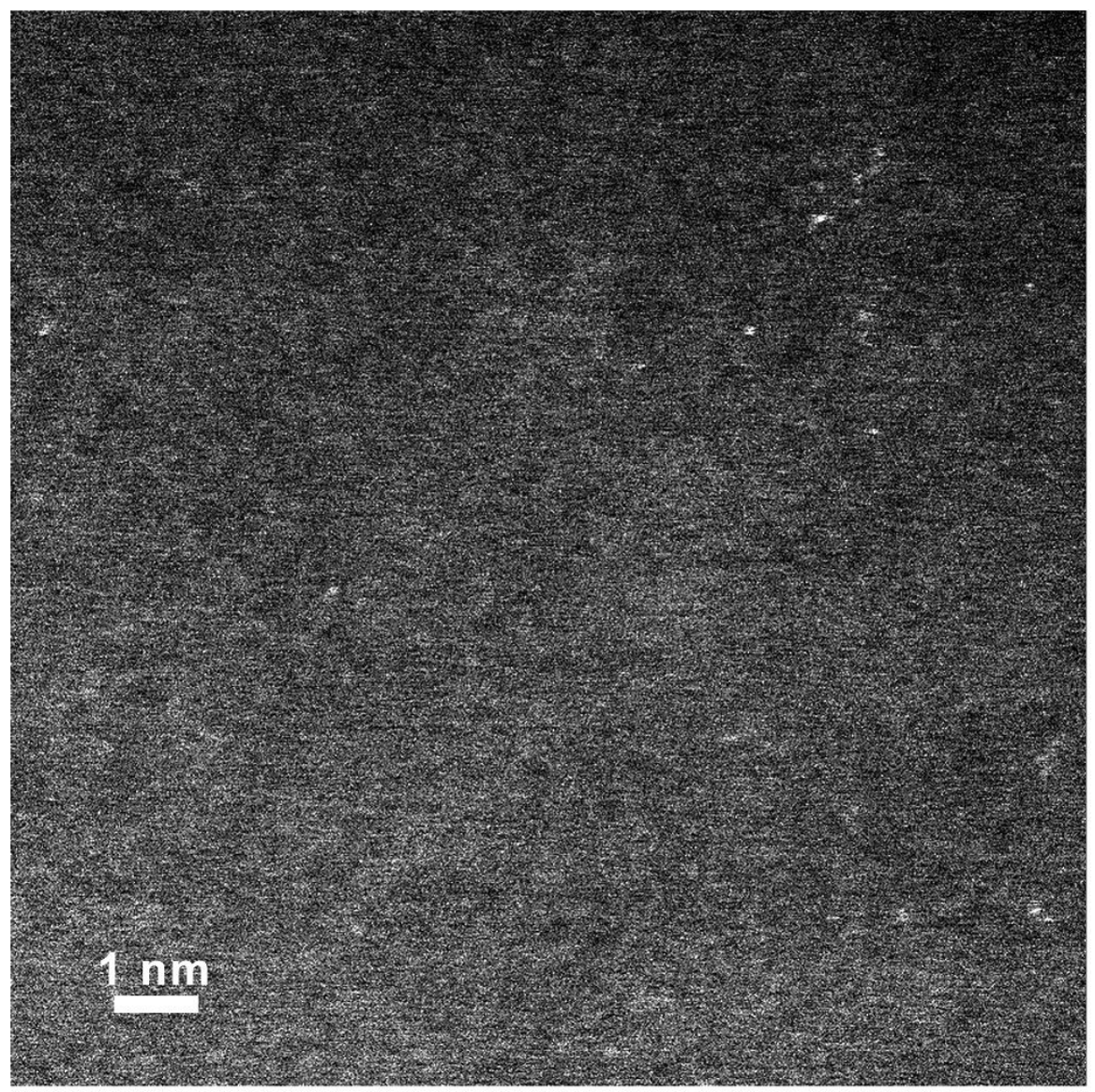

Figure S5. The AC HAADF-STEM image of Ru SAs/S-1. 


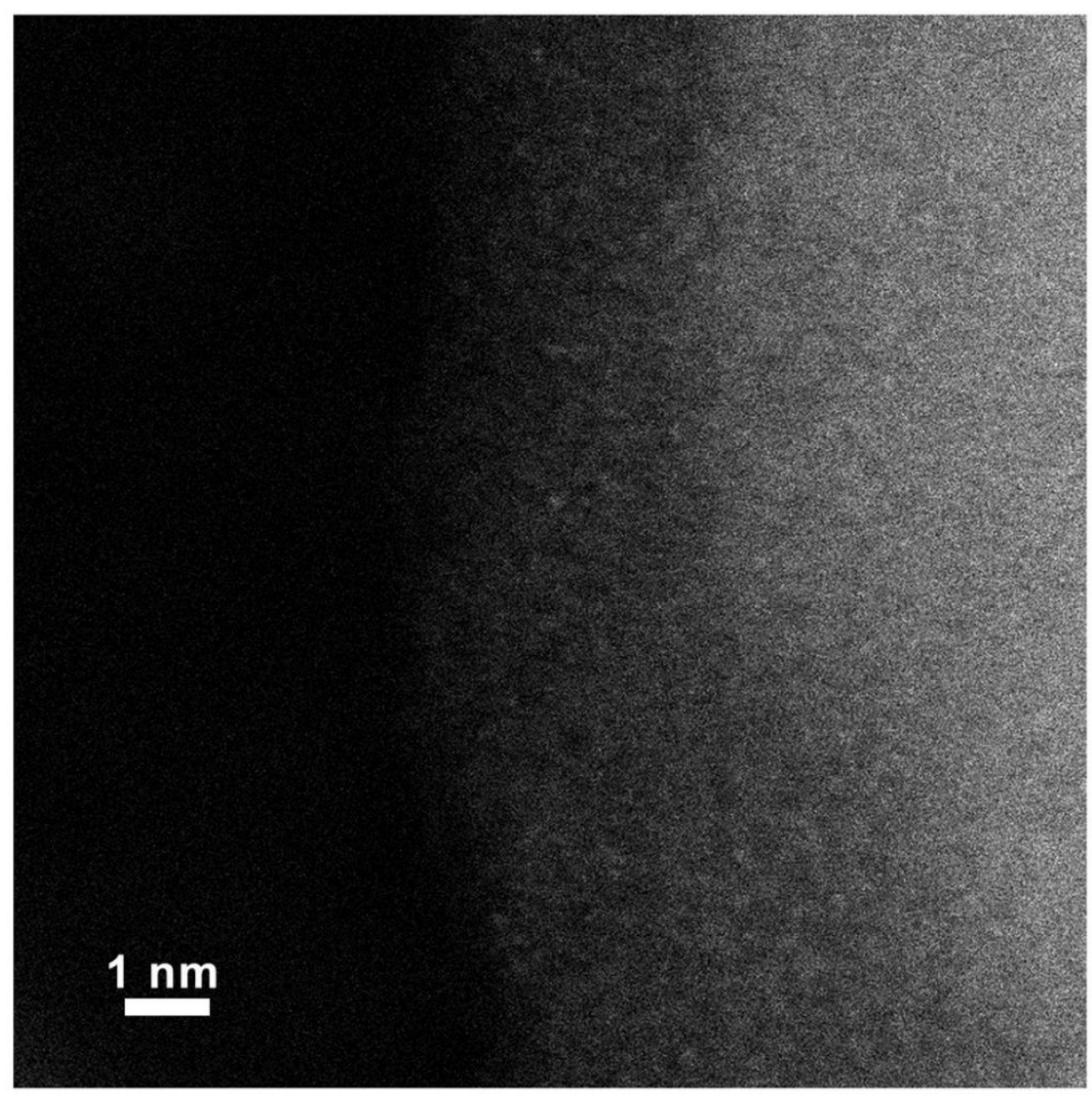

Figure S6. The AC HAADF-STEM image of Ru SAs/S-1-used. 

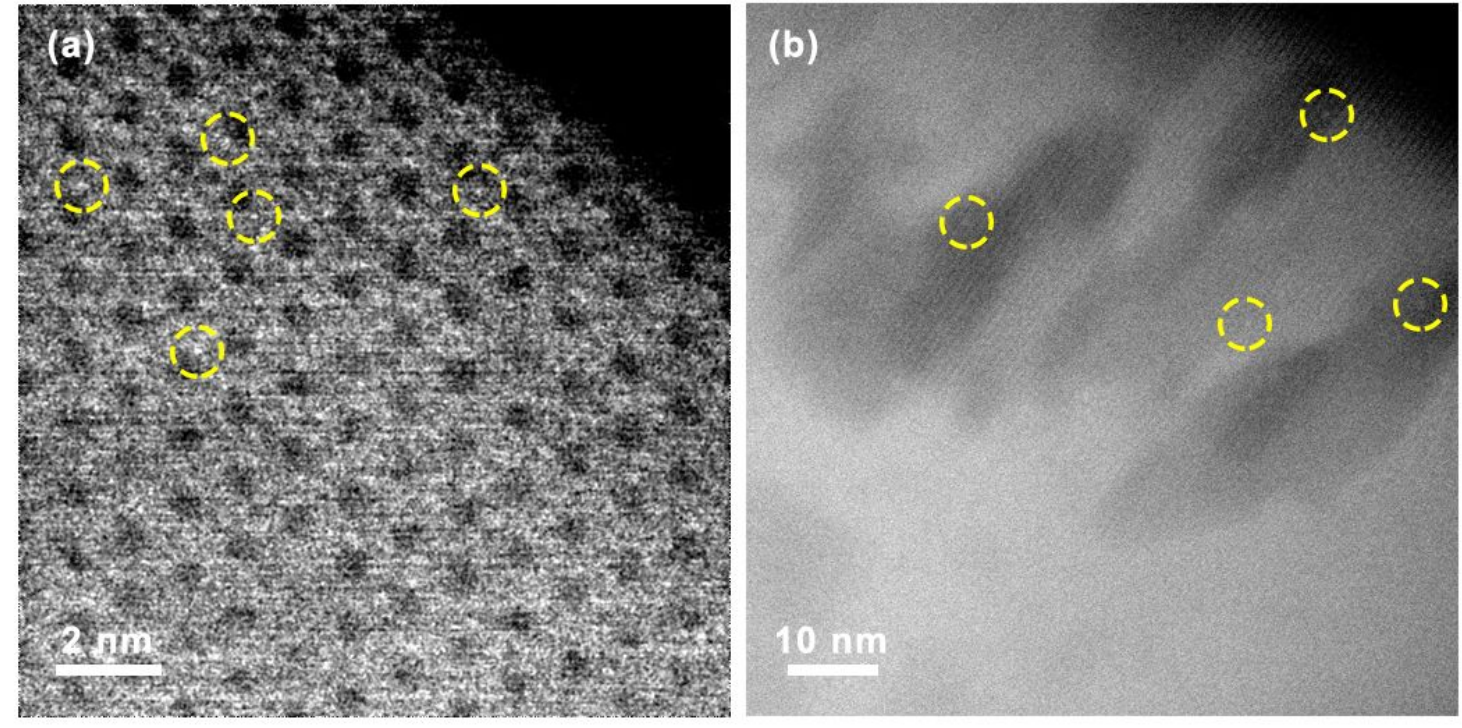

Figure S7. The AC HAADF-STEM images $(a, b)$ of Ru SAs/S-1 after the catalytic reaction for 100 h. 


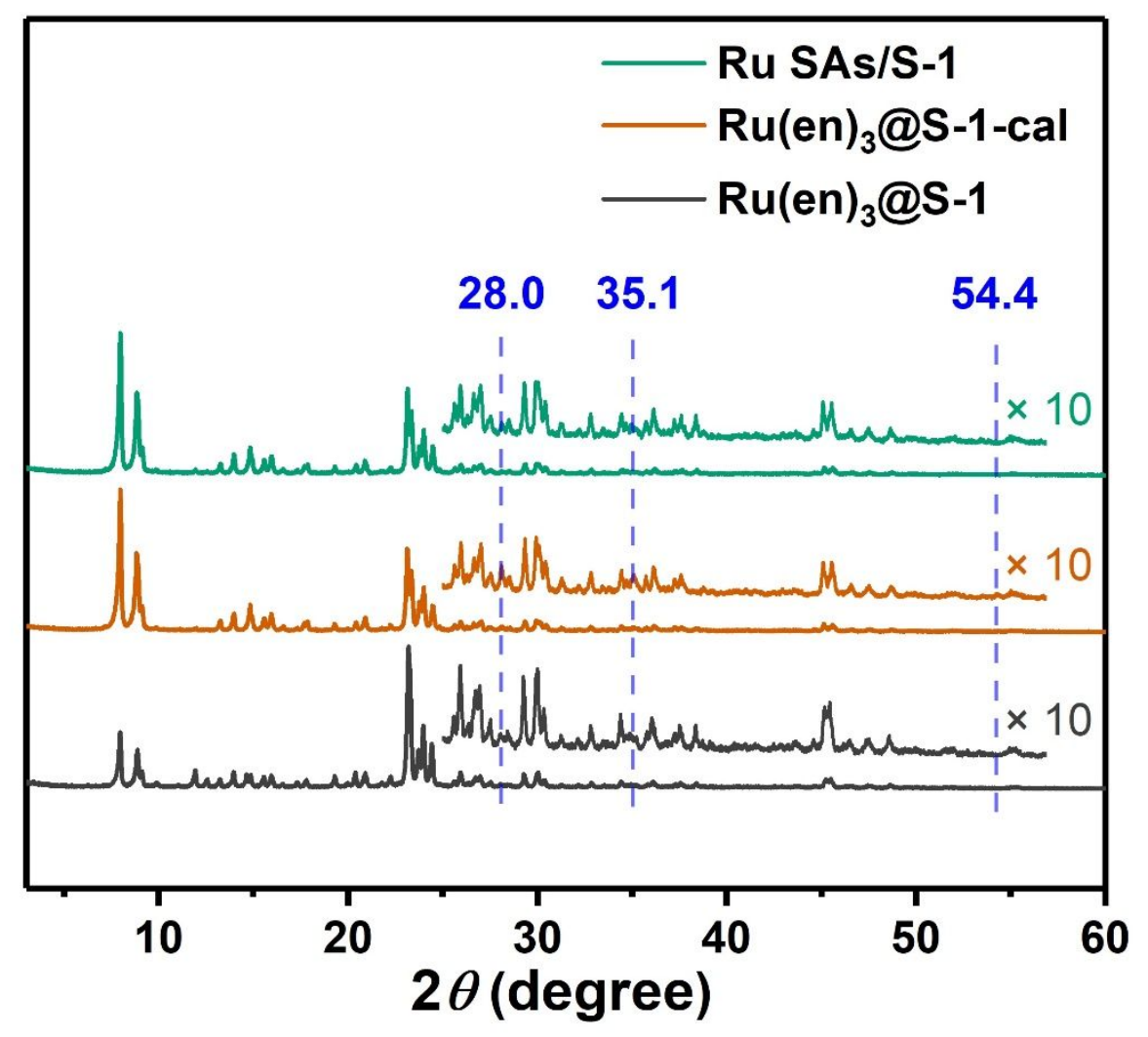

Figure S8. XRD patterns of Ru(en $)_{3} @ S-1, \mathrm{Ru}(\mathrm{en})_{3} @ \mathrm{~S}-1-\mathrm{cal}$ and Ru SAs/S-1, respectively. The XRD pattern of $\mathrm{Ru}(\mathrm{en})_{3} @ \mathrm{~S}-1-\mathrm{cal}$ exhibits characteristic peaks of $\left(\begin{array}{lll}1 & 1 & 0\end{array}\right),\left(\begin{array}{lll}1 & 0 & 1\end{array}\right)$ and $\left(\begin{array}{lll}2 & 1 & 1\end{array}\right)$ reflections for $\mathrm{RuO}_{2}$ at $28.0^{\circ}, 35.1^{\circ}$, and $54.4^{\circ}$, indicating severe sintering caused by the calcination treatment in air atmosphere for removing the OSDA and amine. By contrast, no characteristic peaks of $\mathrm{RuO}_{2}$ are observed in the XRD pattern of Ru SAs/S-1 which is decomposed in the vacuum. 

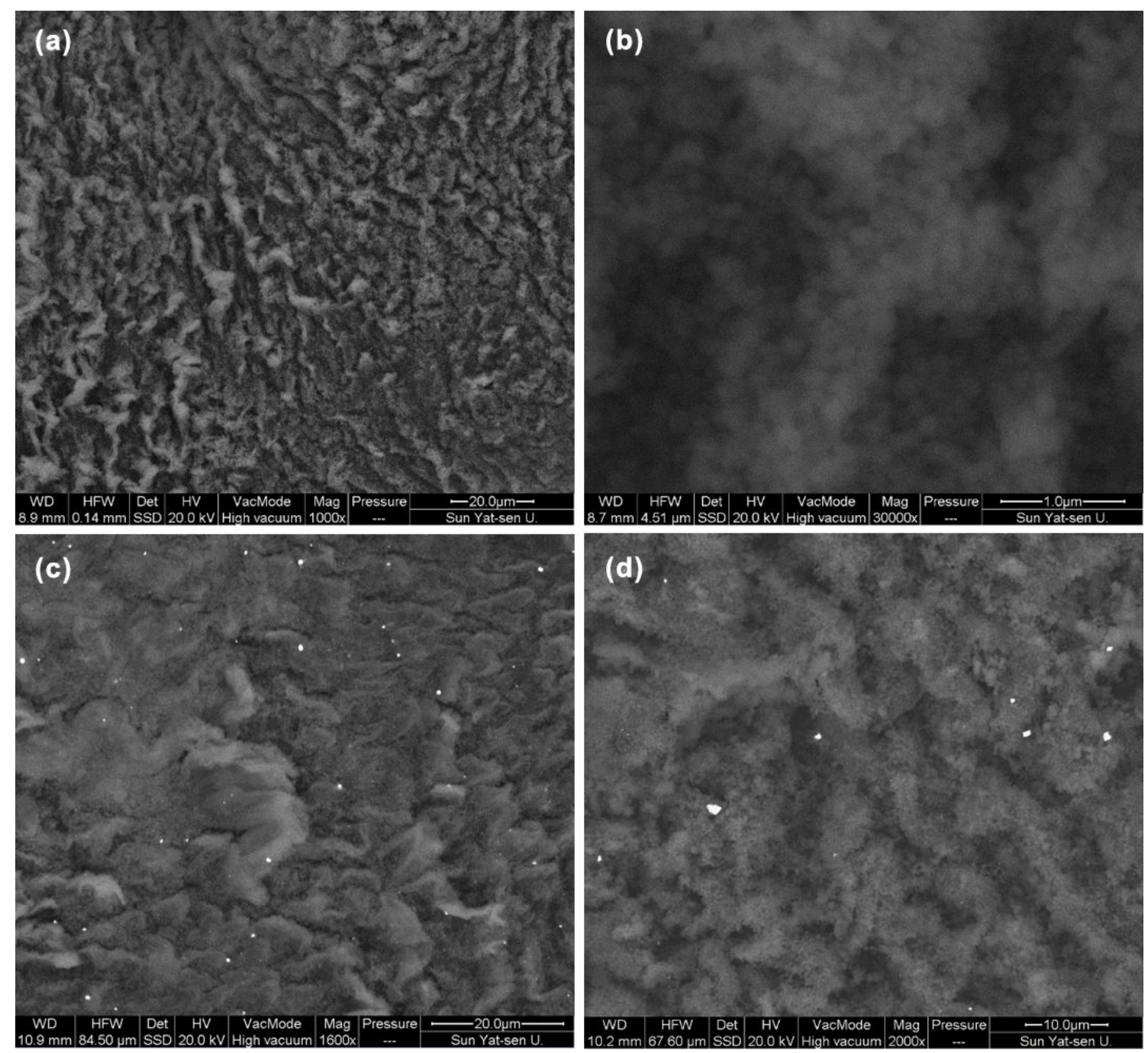

Figure S9. Back-scattered electron (BSE) SEM images of Ru SAs/S-1 (a, b) and Ru(en) $)_{3}$ S-1-cal (c, d). Massive bright spots which correspond to the heavy Ru can be obviously observed on the surface of Ru(en) $)_{3} @ S-1-c a l$, indicating the severe agglomeration of Ru particles. Oppositely, the BSE SEM images of Ru SAs/S-1 do not show any bright spots. 

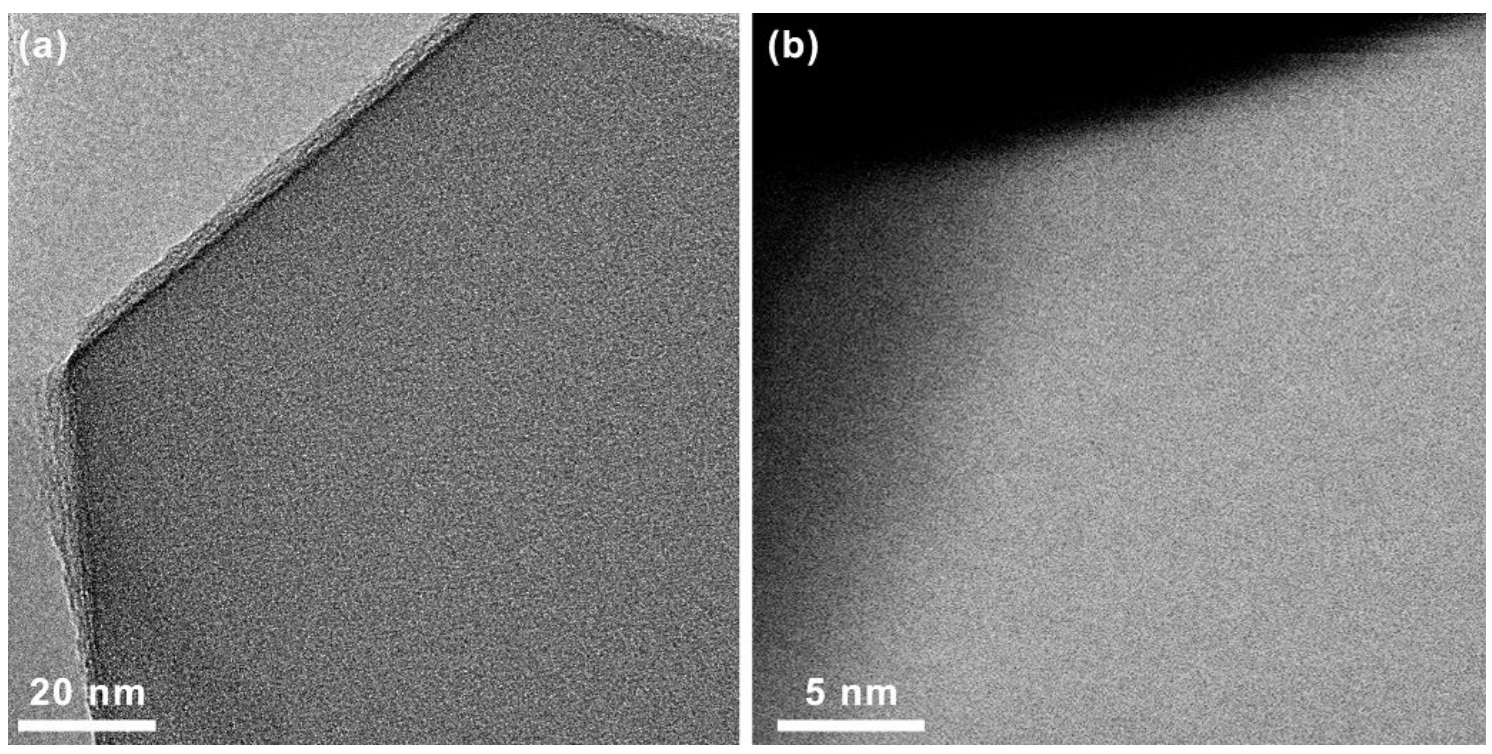

Figure S10. (a, b) High-resolution transmission electron microscope (HR-TEM) of Ru(en) $)_{3}$ S-1 after decomposing in Ar atmosphere with a low flow rate $\left(80 \mathrm{ml} \cdot \mathrm{min}^{-1}\right)$ in the horizontal tube at 723 $\mathrm{K}$. 


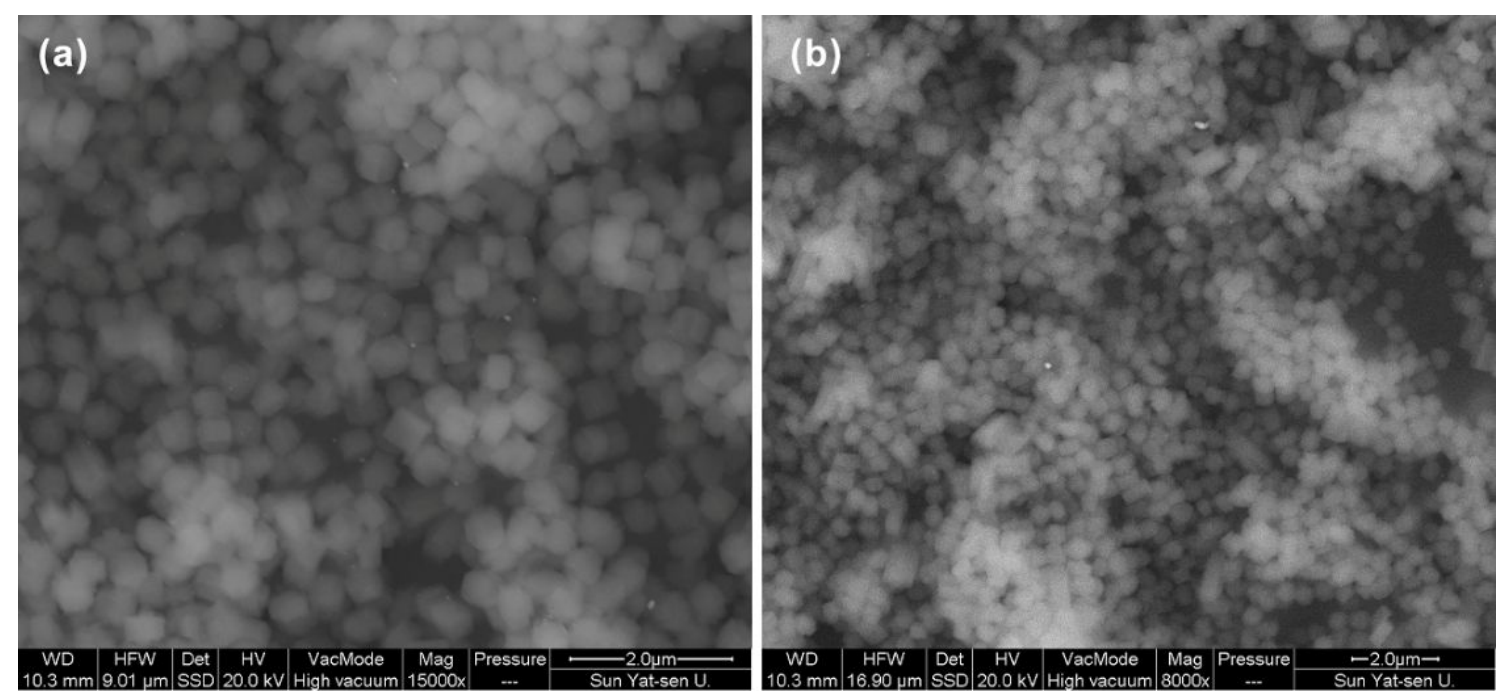

Figure S11. (a, b) BSE SEM images of Ru(en) ${ }_{3} @ S-1$ after decomposing in Ar atmosphere in the vertical fixed bed at $723 \mathrm{~K}$. When the Ru(en) $)_{3} @ \mathrm{~S}-1$ decomposes in a relatively high flow rate with turbulence, nanoparticles are formed outside zeolite surface. 

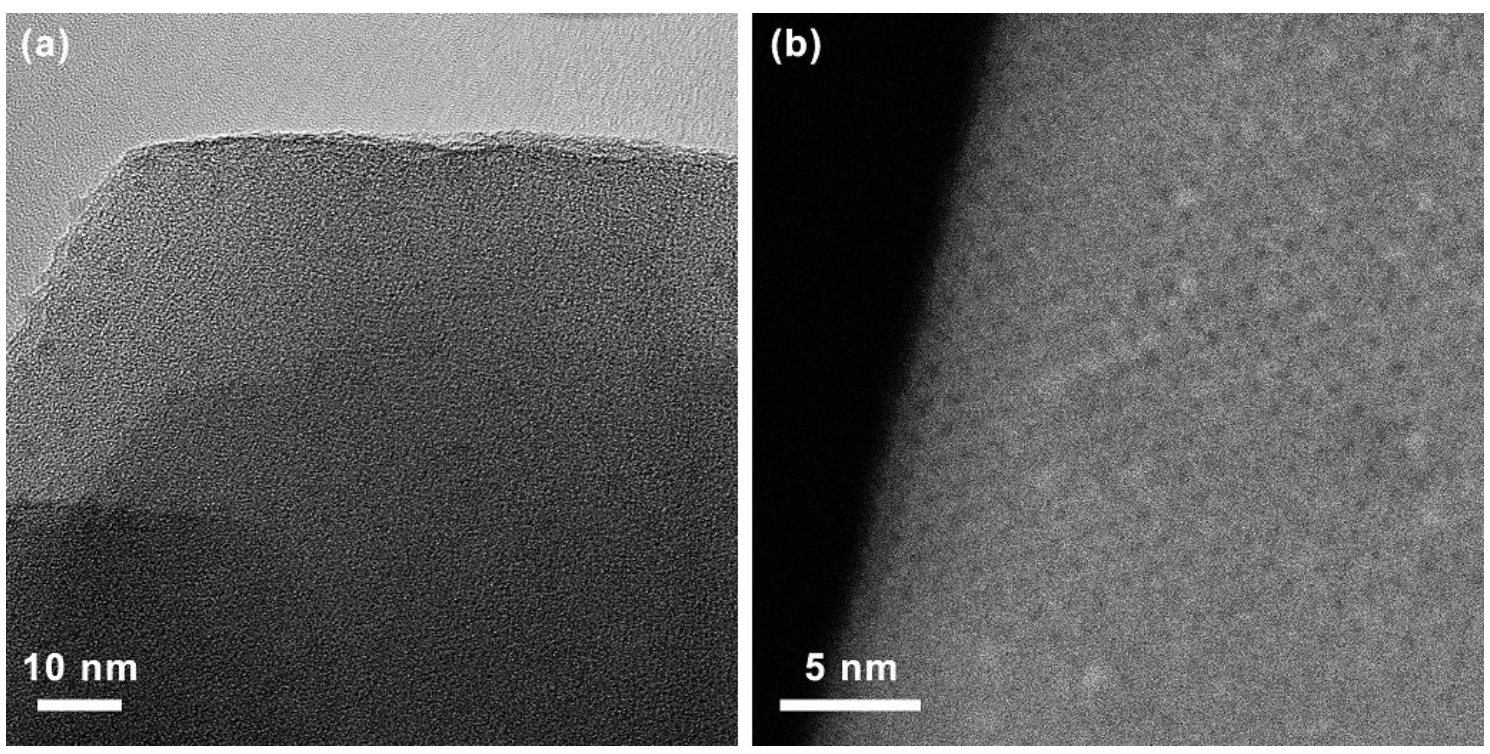

Figure S12. TEM image (a) and STEM image (b) of Ru(en) ( $_{3} \mathrm{~S}-1$ with 0.36 wt\% Ru loading after decomposing in a vacuum atmosphere. Obviously, subnanometre $\mathrm{Ru}$ clusters are formed in the zeolite, indicating the aggregation of $\mathrm{Ru}$ atoms. 

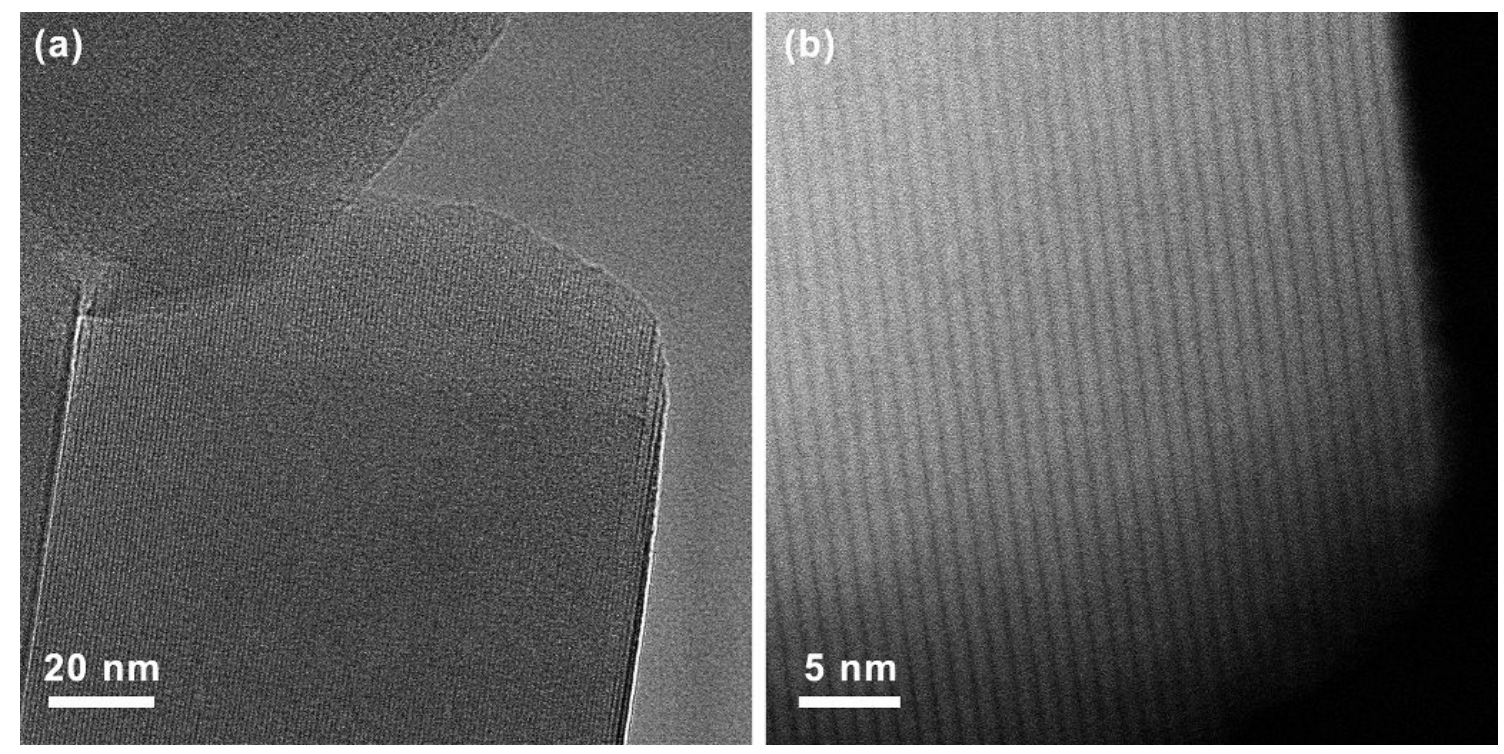

Figure S13. HR-TEM (a) and STEM (b) images of Ru SAs/S-1 after the treatment in $\mathrm{NH}_{3}$ atmosphere with a low flow rate $\left(80 \mathrm{ml} \cdot \mathrm{min}^{-1}\right)$ for $8 \mathrm{~h}$ at $723 \mathrm{~K}$. Although in strong reductive condition at $723 \mathrm{~K}$, the aggregation of $\mathrm{Ru}$ atoms is not observed, indicating the $\mathrm{Ru}$ single atoms remain atomically dispersed on the S-1 support. 

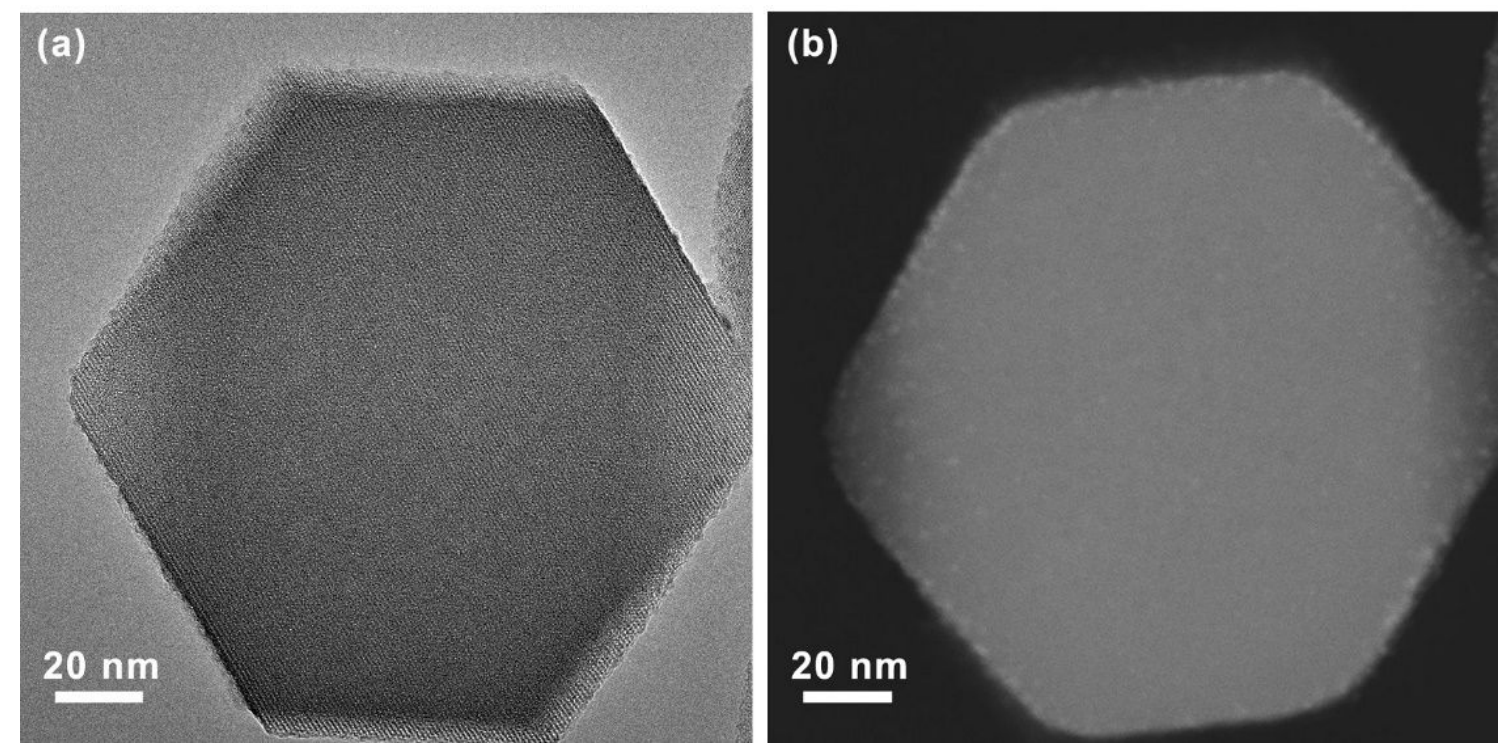

Figure S14. HR-TEM (a) and STEM (b) images of Ru SAs/S-1 after the treatment in $\mathrm{NH}_{3}$ atmosphere with a low flow rate $\left(80 \mathrm{ml} \cdot \mathrm{min}^{-1}\right)$ for $3 \mathrm{~h}$ at $923 \mathrm{~K}$. It shows that well-defined subnanometre clusters $(\sim 1.2 \mathrm{~nm})$ are formed, indicating a dynamic structural transformation of $\mathrm{Ru}$ single atoms to aggregation upon increasing the temperature under strong reductive condition. 


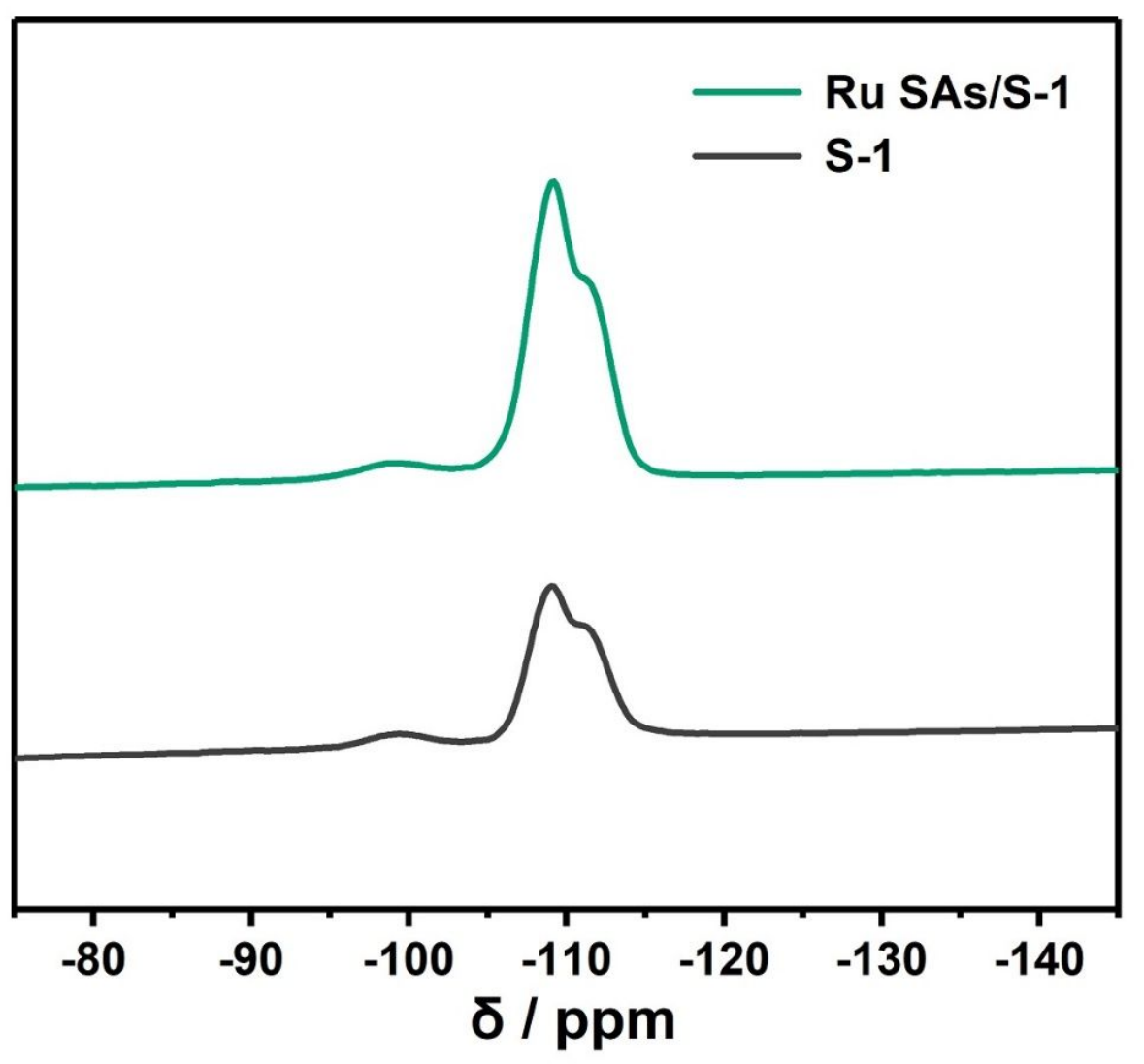

Figure S15. ${ }^{29}$ Si MAS NMR spectra of S-1 and Ru SAs/S-1. The samples of S-1 and Ru SAs/S1 show almost identical ${ }^{29} \mathrm{Si}$ MAS NMR spectra, demonstrating that the Ru complex located in the zeolite channel rather than making more defects. 


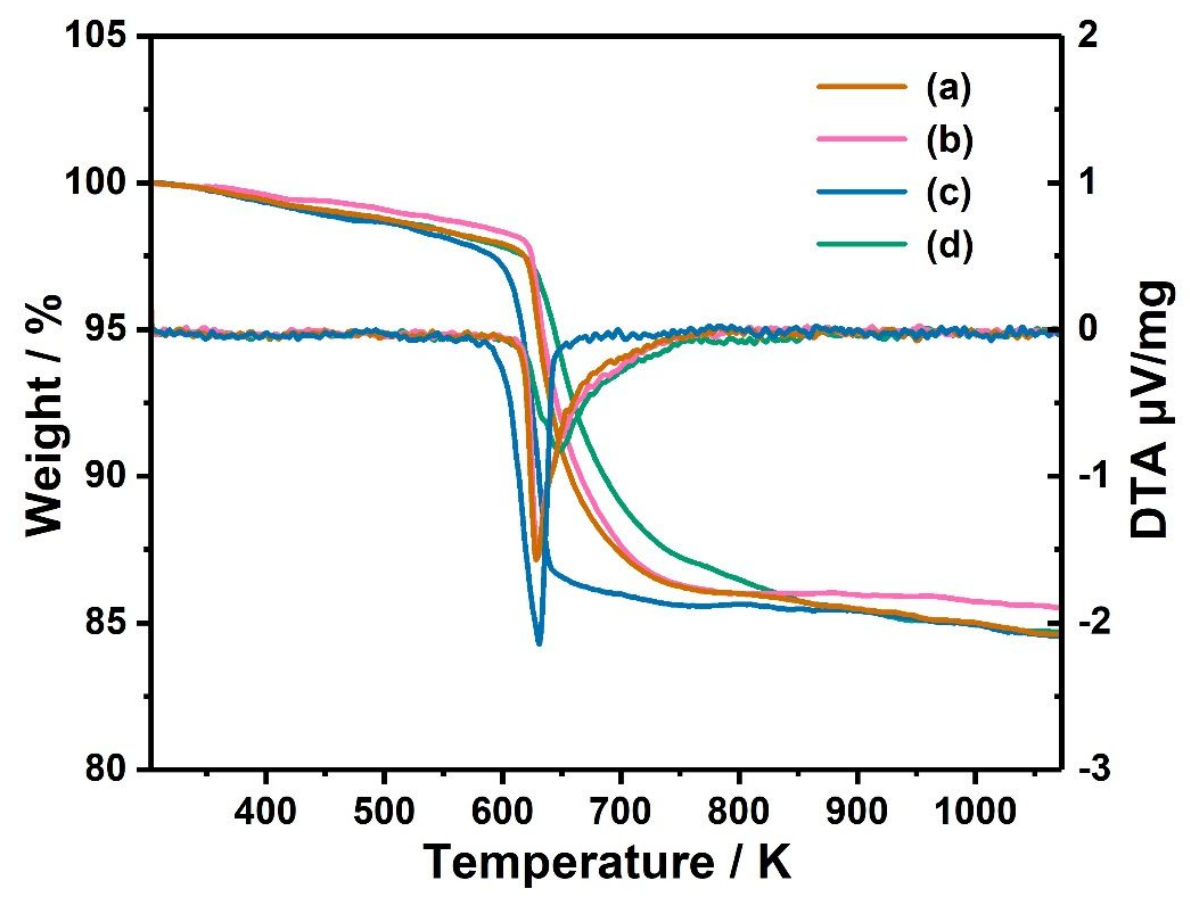

Figure S16. TG/DTA curves of S-1 at air (a) and $\mathrm{N}_{2}$ (b) atmospheres and Ru(en) $)_{3} \mathrm{~S}-1$ in the air (c) and $\mathrm{N}_{2}(\mathrm{~d})$ atmospheres. The Ru(en) $)_{3} @ S$ S-1 and S-1 samples are as-synthesized with the OSDA and amine. The TG/DTA curves of S-1 samples at both $\mathrm{N}_{2}$ and air atmospheres are almost identical, indicating the air atmosphere is replaceable by $\mathrm{N}_{2}$ atmosphere for TPAOH removing. Whereas, the decomposition process of $\mathrm{Ru}(\mathrm{en})_{3} @ \mathrm{~S}-1$ in air atmosphere is obviously faster than that in $\mathrm{N}_{2}$ atmosphere and even faster than S-1 in air atmosphere, which may be attributed to the running away of $\mathrm{Ru}(\mathrm{en})_{3}{ }^{3+}$ or $\mathrm{Ru}$ species during the pyrolysis process. It may result in residual $\mathrm{Ru}$ species outside the surface of zeolite crystals and is also supported by both XRD pattern and BSE SEM image of Ru SAs/S-1-cal. In a word, we can conclude that atomically dispersed sample could be prepared in an inert atmosphere or vacuum condition. Herein, we choose the decomposition condition in vacuum at $723 \mathrm{~K}$ for $12 \mathrm{~h}$ to make sure it is completely decomposed. 


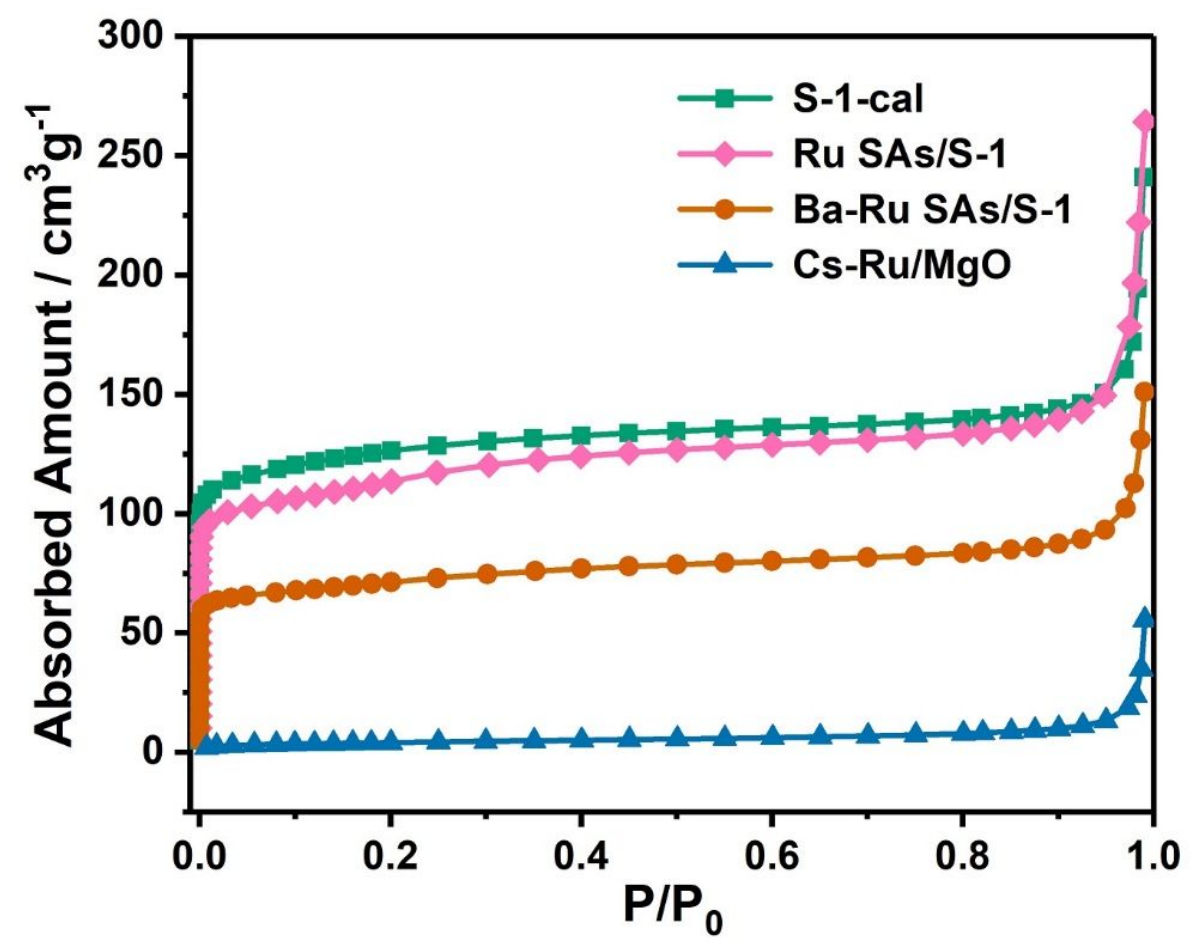

Figure S17. $\mathrm{N}_{2}$ adsorption isotherms of S-1-cal, Ru SAs/S-1, Ba-Ru SAs/S-1 and Cs-Ru/MgO at $77 \mathrm{~K}$. The $\mathrm{N}_{2}$ adsorption isotherm of Ru SAs/S-1 (BET surface area: $426.89 \mathrm{~m}^{2} \mathrm{~g}^{-1}$; pore volume: $0.181 \mathrm{~cm}^{3} \mathrm{~g}^{-1}$ ) is similar to that of S-1 (BET surface area: $481.75 \mathrm{~m}^{2} \mathrm{~g}^{-1}$; pore volume: $\left.0.184 \mathrm{~cm}^{3} \mathrm{~g}^{-1}\right)$. This results further verify that the OSDA and amine in the channels of Ru SAs/S1 are almost completely decomposed. 


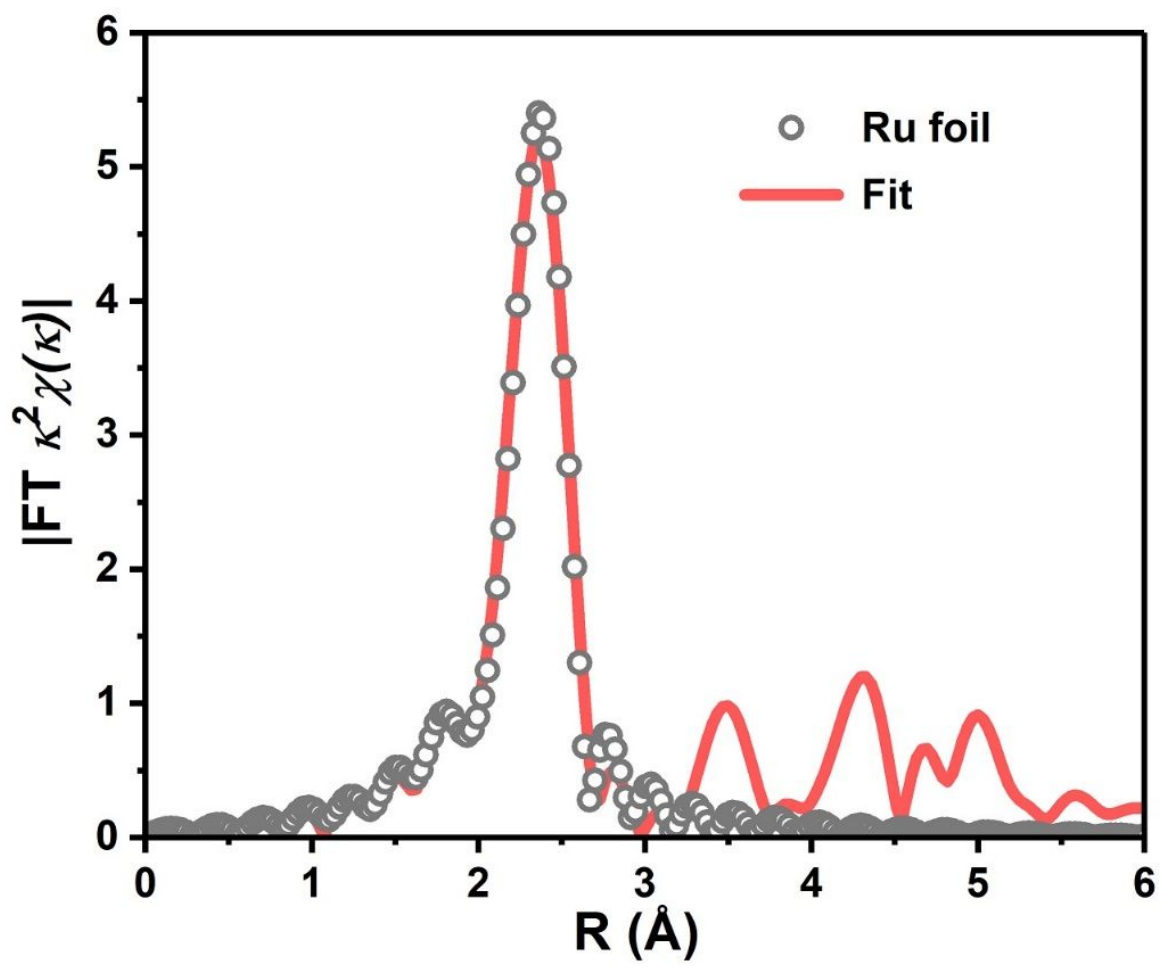

Figure S18. The corresponding EXAFS fitting curve and experimental data of Ru foil. 


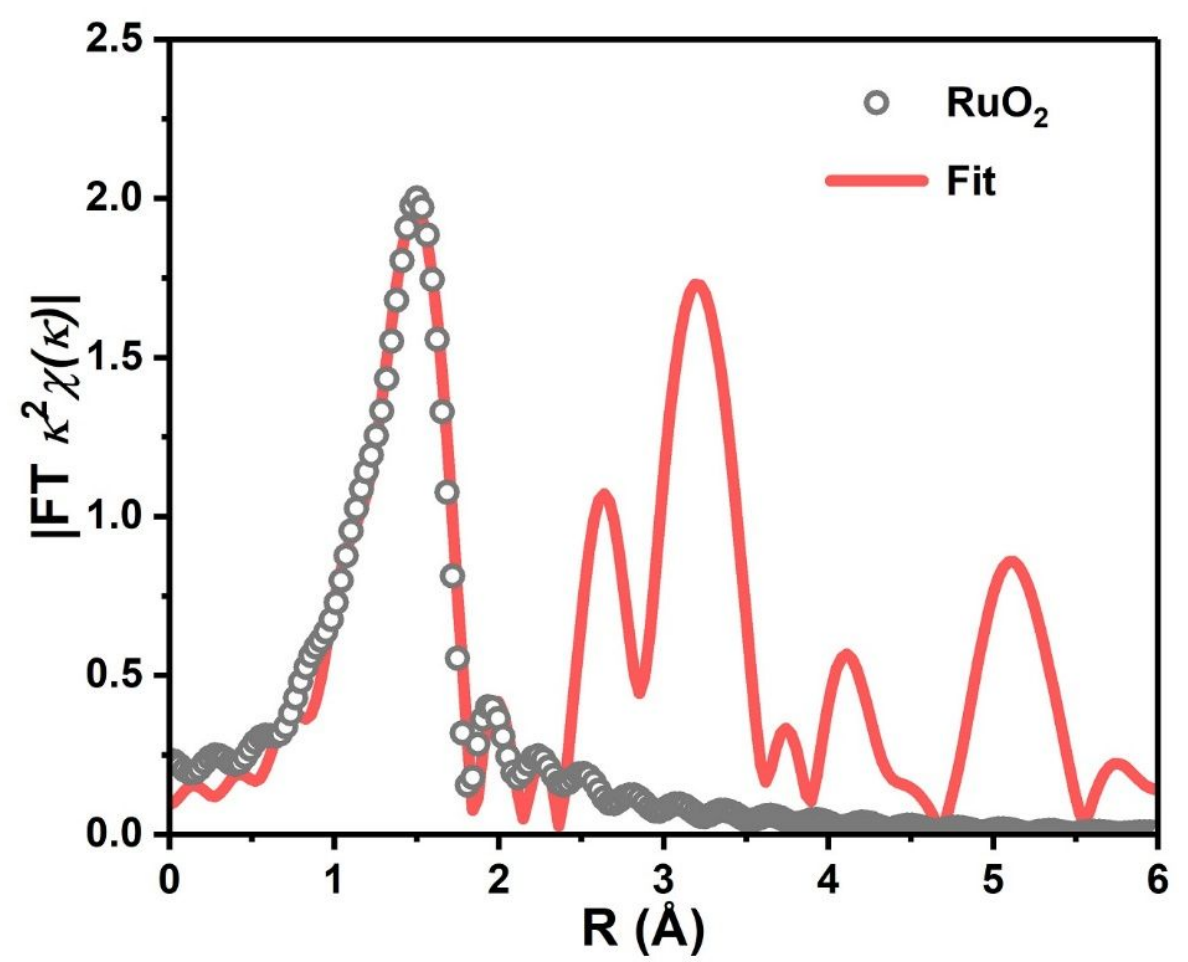

Figure S19. The corresponding EXAFS fitting curve and experimental data for the first coordination sphere of $\mathrm{RuO}_{2}$. 


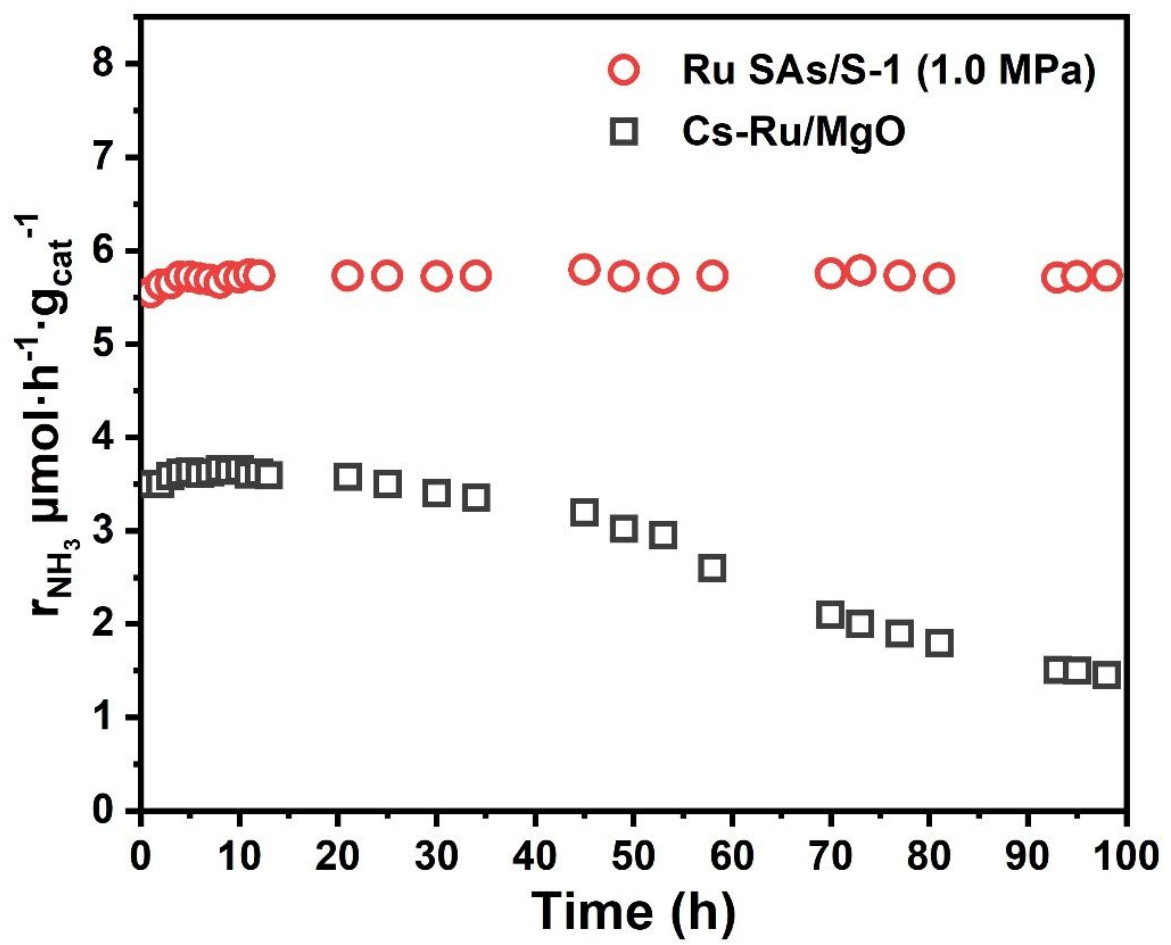

Figure S20. Time dependence of the catalytic activities of $\mathrm{Ru} \mathrm{SAs} / \mathrm{S}-1$ and $\mathrm{Cs}-\mathrm{Ru} \mathrm{MgO}$ at $633 \mathrm{~K}$ under $1.0 \mathrm{MPa}$ with a total flow rate of $60 \mathrm{ml} \cdot \mathrm{min}^{-1}$. 


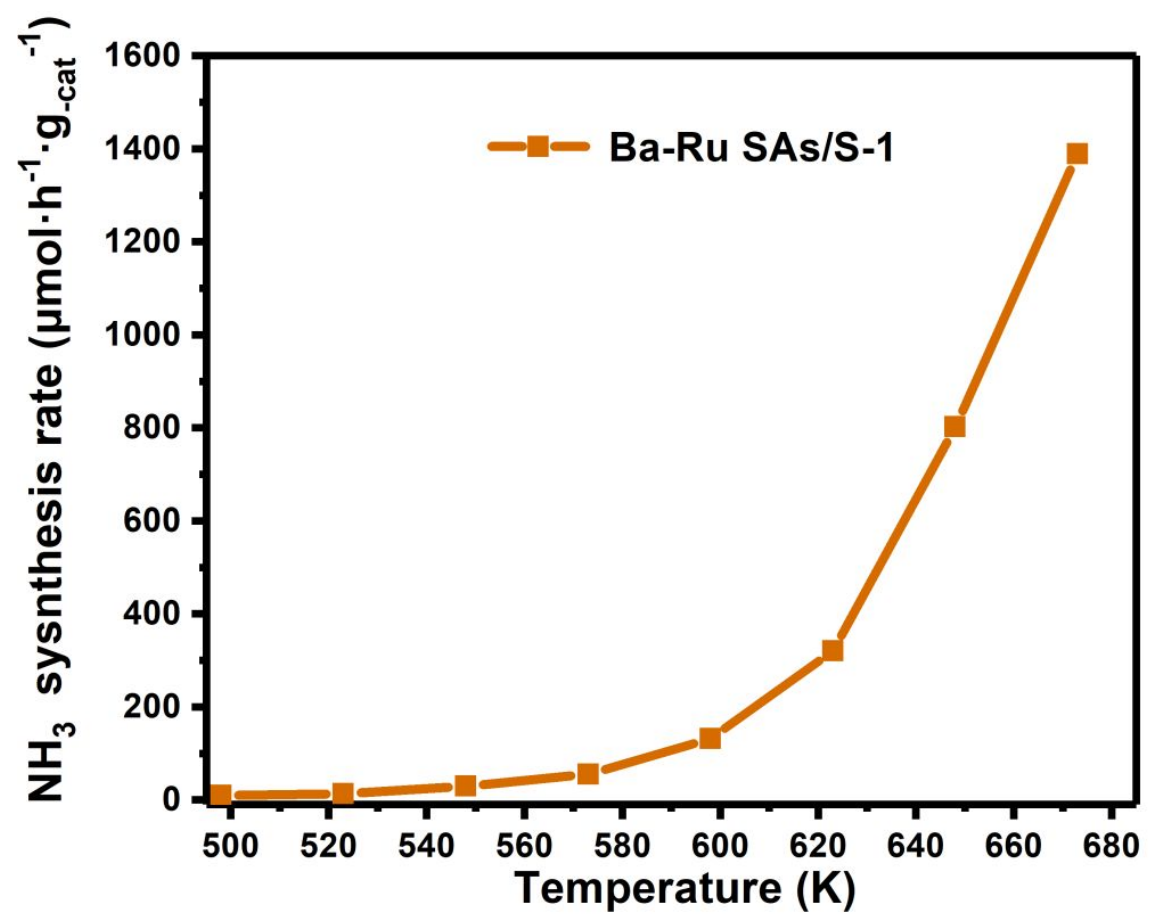

Figure S21. Temperature dependence of $\mathrm{NH}_{3}$ synthesis rate over Ba-Ru SAs/S-1 at ambient pressure $(0.1 \mathrm{MPa})$. Reaction conditions: catalyst, $0.2 \mathrm{~g} ; \mathrm{H}_{2}: \mathrm{N}_{2}=3: 1\left(60 \mathrm{ml} \cdot \mathrm{min}^{-1}\right)$; WHSV of $18,000 \mathrm{ml} \cdot \mathrm{g}^{-1} \cdot \mathrm{h}^{-1}$. 


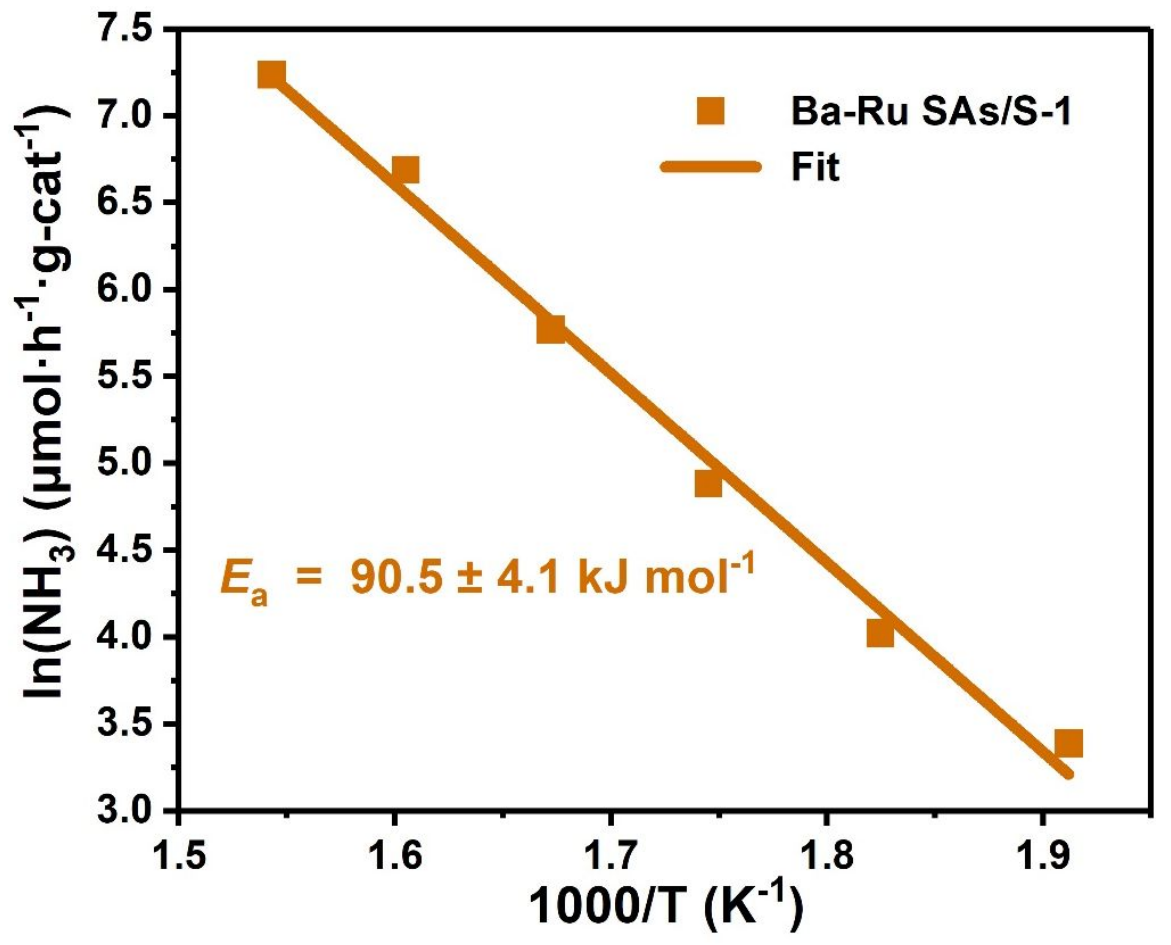

Figure S22. Arrhenius plots of Ba-Ru SAs/S-1 in the temperature range 523-648 K. The error range is $\pm 5 \%$. The $E_{a}$ of Ba-Ru SAs/S-1 is estimated to be $90.5 \mathrm{~kJ} \cdot \mathrm{mol}^{-1}$ from the Arrhenius plot, which is smaller than that of Ru SAs $/ \mathrm{S}-1\left(55 \mathrm{~kJ} \cdot \mathrm{mol}^{-1}\right)$, revealing a different reaction mechanism for the introduction of Ba promoter. 


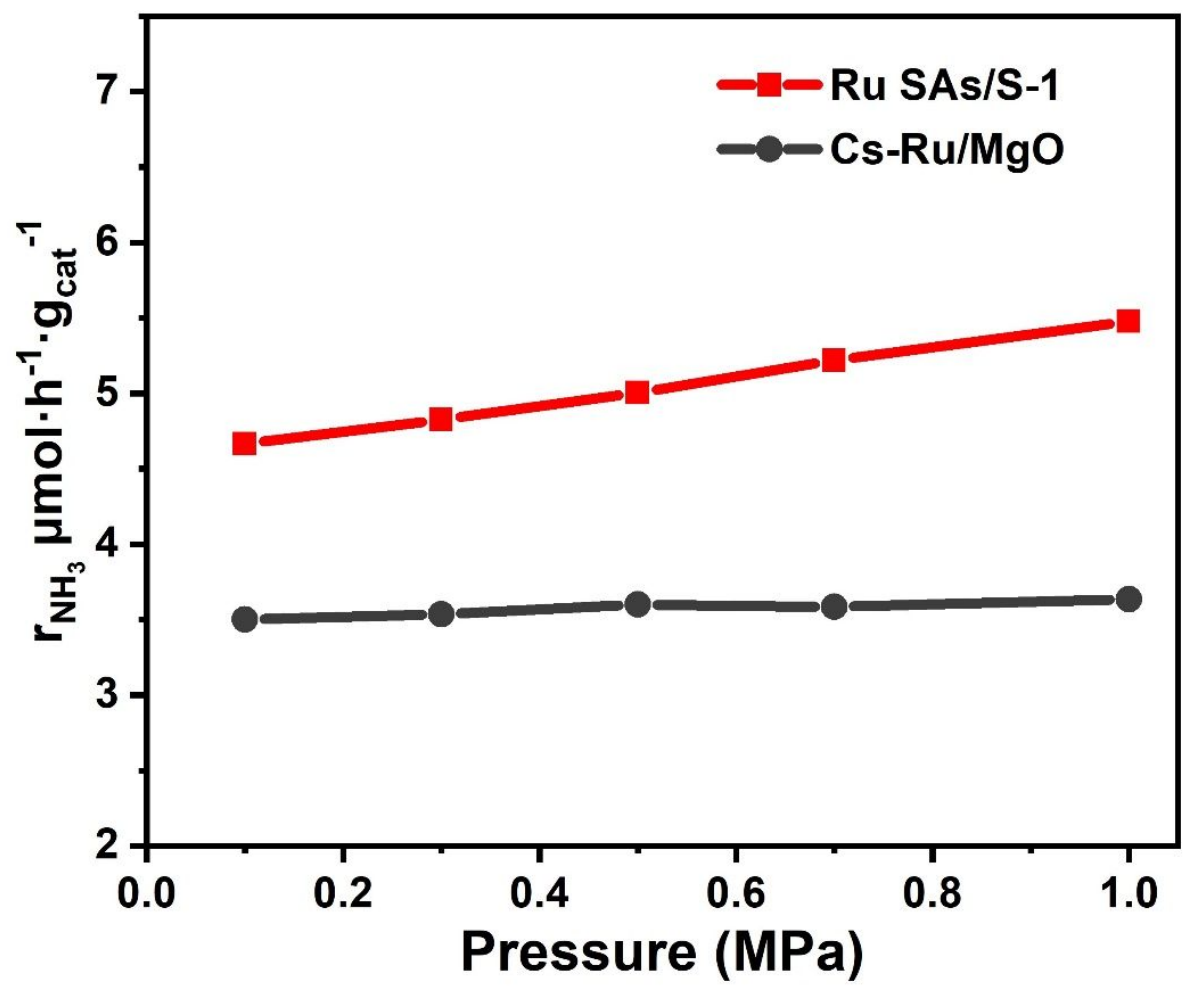

Figure S23. Pressure dependence of $\mathrm{NH}_{3}$ synthesis rate over $\mathrm{Ru} \mathrm{SAs} / \mathrm{S}-1$ and $\mathrm{Cs}-\mathrm{Ru} / \mathrm{MgO}$ in the range of $0.1 \mathrm{MPa}-1.0 \mathrm{MPa}$ at $633 \mathrm{~K}$ with a total flow rate of $60 \mathrm{ml} \cdot \mathrm{min}^{-1}$. 


\section{Supplementary Tables}

Table S1. Structure parameters of $\mathrm{Ru}$ foil, $\mathrm{RuO}_{2}, \mathrm{Ru} \mathrm{SAs} / \mathrm{S}-1$, and $\mathrm{Ru} \mathrm{SAs} / \mathrm{S}-1$-used extracted from the EXAFS fitting. $\left(S_{0}^{2}=0.9\right)$

\begin{tabular}{|c|c|c|c|c|c|c|}
\hline sample & path & $N$ & $R(\AA)$ & $\Delta E_{0}(\mathrm{eV})$ & $\sigma^{2}\left(10^{-3} \AA^{2}\right)$ & $R$ factor $(\%)$ \\
\hline $\mathrm{Ru}$ foil & $\mathrm{Ru}-\mathrm{Ru}$ & $6^{*}$ & $2.68 \pm 0.002$ & $-4.28 \pm 0.74$ & $4.23 \pm 0.08$ & 0.004 \\
\hline $\mathrm{RuO}_{2}$ & $\mathrm{Ru}-\mathrm{O}$ & $6^{*}$ & $1.98 \pm 0.01$ & $-2.44 \pm 1.80$ & $3.11 \pm 0.74$ & 0.019 \\
\hline $\mathrm{Ru} \mathrm{SAs} / \mathrm{S}-1$ & $\mathrm{Ru}-\mathrm{O}$ & $4.1 \pm 0.6$ & $2.01 \pm 0.02$ & \multirow{2}{*}{$1.70 \pm 2.42$} & \multirow{2}{*}{4.0} & \multirow{2}{*}{0.04} \\
\hline Ru SAs/S-1-used & $\mathrm{Ru}-\mathrm{O}$ & $4.1 \pm 0.5$ & $2.01 \pm 0.02$ & & & \\
\hline
\end{tabular}

* The coordination number $(N)$ of Ru is fixed according to the crystal structure. 
Table S2. Catalytic performance of Ru catalysts on various supports.

\begin{tabular}{|c|c|c|c|c|c|c|}
\hline Catalyst & $\begin{array}{l}\text { Surface area } \\
\left(\mathrm{m}^{2} \cdot \mathrm{g}^{-1}\right)\end{array}$ & $\begin{array}{c}\text { Ru loading } \\
\quad(\mathrm{wt} \%)^{a}\end{array}$ & $\begin{array}{c}\mathrm{NH}_{3} \text { synthesis } \\
\text { rate }\left(\mu \mathrm{mol} \cdot \mathrm{g}^{-}\right. \\
\left.{ }^{1} \cdot \mathrm{h}^{-1}\right)\end{array}$ & $\begin{array}{c}\text { TOF } \\
\left(\times 10^{-3} \mathrm{Ru}\right. \\
\left.\text { atom }^{-1} \cdot \mathrm{s}^{-1}\right)^{b}\end{array}$ & $\begin{array}{c}E_{\mathrm{a}} \\
\left(\mathrm{kJ} \cdot \mathrm{mol}^{-1}\right)^{c}\end{array}$ & Ref \\
\hline $\mathrm{Ru} \mathrm{SAs} / \mathrm{S}-1^{*}$ & 425 & 0.27 & 6.1 & 0.064 & 55.4 & \\
\hline $\mathrm{Ba}-\mathrm{Ru} \mathrm{SAs} / \mathrm{S}-1^{\dagger}$ & 272 & 0.23 & 1390 & 16.96 & 90.5 & $\begin{array}{l}\text { this } \\
\text { work }\end{array}$ \\
\hline Cs- $\mathrm{Ru} / \mathrm{MgO}$ * & 14 & 0.27 & 4.6 & 0.047 & 100.9 & \\
\hline $\mathrm{Cs}-\mathrm{Ru} / \mathrm{MgO}{ }^{\ddagger}$ & 10 & 6.0 & 3353 & 1.57 & 73.0 & \multirow{6}{*}{$\begin{array}{c}\text { Ref. } \\
1\end{array}$} \\
\hline $\mathrm{Ru} / \gamma-\mathrm{Al}_{2} \mathrm{O}_{3}^{*}$ & 170 & 6.00 & 51 & 0.020 & 64.4 & \\
\hline $\mathrm{Ba}-\mathrm{Ru} / \mathrm{AC}$ & 310 & 1.00 & 148 & 0.42 & 88.8 & \\
\hline $\mathrm{Ru} / \mathrm{CaO}^{\ddagger}$ & 3 & 1.5 & 158 & 0.30 & 120.1 & \\
\hline $\mathrm{Ru} / \mathrm{C} 12 \mathrm{~A} 7: \mathrm{O}^{2-\$}$ & $1 \sim 2$ & 1.20 & 546 & 1.28 & 104.6 & \\
\hline $\mathrm{Ru} / \mathrm{C} 12 \mathrm{~A} 7: \mathrm{e}^{-*}$ & $1 \sim 2$ & 0.30 & 1027 & 11.09 & 40.0 & \\
\hline
\end{tabular}

${ }^{\mathrm{a}} \mathrm{Ru}$ content is determined by ICP-AES (ref. catalyst) and ICP-MS (in this work). ${ }^{\mathrm{b}} \mathrm{TOF}$ is calculated from the rate of ammonia synthesis divided by the total number of Ru atoms deposited on the catalysts. ${ }^{c} E_{a}$ is calculated from Arrhenius plots of the ammonia synthesis rate within the temperature range of 593-673 $\mathrm{K}$ for ref. catalyst, 548-648 $\mathrm{K}$ for Ru SAs/S-1 and Cs-Ru/MgO, and 523-648 K for Ba-Ru SAs/S-1, respectively. $\mathrm{NH}_{3}$ synthesis conditions: ${ }^{*} \mathrm{Ru} \mathrm{SAs} / \mathrm{S}-1$ and $\mathrm{Cs}-\mathrm{Ru} / \mathrm{MgO}$ : catalyst $(0.2 \mathrm{~g})$, synthesis gas $\left(\mathrm{H}_{2} / \mathrm{N}_{2}=3,60 \mathrm{ml} \cdot \mathrm{min}^{-1}\right)$, reaction temperature $(648 \mathrm{~K})$, pressure $(0.1 \mathrm{MPa}){ }^{\dagger} \mathrm{Ba}-\mathrm{Ru} \mathrm{SAs} / \mathrm{S}-1$ catalyst $(0.2$ g), synthesis gas $\left(\mathrm{H}_{2} / \mathrm{N}_{2}=3,60 \mathrm{ml} \cdot \mathrm{min}^{-1}\right)$, reaction temperature $(673 \mathrm{~K})$, pressure $(0.1 \mathrm{MPa})$. ${ }^{\star}$ ref. catalyst: catalyst $(0.2 \mathrm{~g})$, synthesis gas $\left(\mathrm{H}_{2} / \mathrm{N}_{2}=3,60 \mathrm{ml} \cdot \mathrm{min}^{-1}\right)$, reaction temperature $(673 \mathrm{~K})$, pressure $(0.1 \mathrm{MPa})$. 
Supplementary Table 3. DFT-calculated $\mathrm{NH}_{3}$ synthesis.

\begin{tabular}{|c|c|c|c|}
\hline Structure & State & $G(e V)$ & $G(e V)$ \\
\hline $\mathrm{A}$ & 0 -surface & 0 & \\
\hline B & $\mathrm{N}_{2}$ & -0.57 & $E_{a d}=0.57$ \\
\hline $\mathrm{C}$ & $\mathrm{N}_{2}+\mathrm{H}_{2}$ & -0.79 & $E_{\text {int }}=0.22$ \\
\hline $\mathrm{TS}(\mathrm{I})$ & $\mathrm{N}_{2}+\mathrm{H}_{2}$ & 0.09 & $E_{a}=0.88$ \\
\hline $\mathrm{D}$ & $\mathrm{N}_{2} \mathrm{H}_{2}$ & -0.56 & \\
\hline E & $\mathrm{N}_{2} \mathrm{H}_{2}+\mathrm{H}_{2}$ & -0.78 & \\
\hline $\mathrm{TS}(\mathrm{II})$ & $\mathrm{N}_{2} \mathrm{H}_{2}+\mathrm{H}_{2}$ & -0.1 & $E_{a}=0.68$ \\
\hline $\mathrm{F}$ & $\mathrm{NH}-\mathrm{NH}_{3}$ & -1.72 & \\
\hline G & $\mathrm{NH}$ & -1.571 & \\
\hline $\mathrm{H}$ & $\mathrm{NH}+\mathrm{H}_{2}$ & -1.771 & \\
\hline TS(III) & $\mathrm{NH}+\mathrm{H}_{2}$ & -1.291 & $E_{a}=0.48$ \\
\hline I & $\mathrm{NH}_{3}$ & -3.03 & \\
\hline A & surface & -2.56 & \\
\hline
\end{tabular}

The reaction follows the proposed mechanism. $E_{a d}$ is adsorption energy, $E_{\text {int }}$ is interaction energy, more positive mean stronger adsorption or interaction, $E_{a}$ is activation energy, TS is reaction transition state.

\section{Reference}

(1) Kitano, M.; Inoue, Y.; Yamazaki, Y.; Hayashi, F.; Kanbara, S.; Matsuishi, S.; Yokoyama, T.; Kim, S. W.; Hara, M.; Hosono, H. Ammonia synthesis using a stable electride as an electron donor and reversible hydrogen store. Nat. Chem. 2012, 4, 934-940. 